\title{
Metachronous Malignant Neoplasm
}

National Cancer Institute

\section{Source}

National Cancer Institute. Metachronous Malignant Neoplasm. NCI Thesaurus. Code C38156.

A malignant tumor that arises at a site separate from another, primary malignant tumor in the same anatomic system. It is not clear if metachronous malignant neoplasms represent new primary tumors or metastatic disease. Examples include metachronous osteosarcoma of the bones that develops in patients with known primary bone osteosarcoma, and metachronous Wilms' tumor that affects the opposite kidney in patients with a history of Wilms' tumor. 